BLANK, A.F.; CARVALHO FILHO, J.L.S.; SANTOS NETO, A.L.; ALVES, P.B.; ARRIGONI-BLANK, M.F.; SILVA-MANN, R.; MENDONÇA, M.C. Caracterização morfológica e agronômica de acessos de manjericão e alfavaca. Horticultura Brasileira, Brasília, v.22, n.1, p. 113-116, jan-mar 2004.

\title{
Caracterização morfológica e agronômica de acessos de manjericão e alfavaca
}

\author{
Arie F. Blank; José L.S. de Carvalho Filho; Antônio L. dos Santos Neto; Péricles B. Alves; Maria de \\ Fátima Arrigoni-Blank; Renata Silva-Mann; Marcelo da C. Mendonça \\ UFS, Av. Marechal Rondon s/n, Bairro Jardim Rosa Elze, 49100-000 São Cristóvão-SE; E-mail: afblank@ufs.br
}

\section{RESUMO}

O manjericão (Ocimum basilicum L.) pode ser considerado cultura anual ou perene, conforme o local de cultivo. Existem diversas finalidades para seu uso na culinária, como planta ornamental, medicinal e aromática, sendo o seu oleo essencial valorizado no mercado internacional pelo teor de linalol. Caracterizou-se morfológica e agronômicamente, acessos de Ocimum sp. visando a seleção de genótipos com alto rendimento de óleo essencial rico em linalol. $\mathrm{O}$ delineamento experimental foi de blocos casualizados, com duas repetições, avaliando 55 genótipos do Banco de Germoplasma de Ocimum da UFS. Avaliou-se a altura de plantas, peso da matéria seca da parte aérea, teor e rendimento de óleo essencial. Observouse grande diversidade entre os genótipos para todas as variáveis morfológicas e agronômicas avaliadas. Houve grande amplitude entre os genótipos quanto ao teor de óleo essencial, variando de 0,202 a $2,536 \mathrm{ml} / 100 \mathrm{~g}$ e para o rendimento de óleo essencial, variando de 1,103 a 21,817 1/ha. Avaliando as variáveis teor e rendimento de óleo essencial de $O$. basilicum pode-se selecionar os genótipos NSL6421, PI197442, PI358464, PI414194, PI531396 e 'Fino Verde' para o programa de melhoramento genético que visa a obtenção de novas cultivares de manjericão com alto rendimento de óleo essencial rico em linalol.

Palavras-chave: Ocimum sp., germoplasma, diversidade, óleo essencial.

\begin{abstract}
Morphologic and agronomic characterization of basil accessions

The sweet basil (Ocimum basilicum L.), can be an annual or a perennial plant depending on the place where it is grown. This plant has several culinary, ornamental, medicinal and aromatic uses. The value of its essential oil in the international market depends on the percentage of linalool. We characterized the morphologic and agronomic qualities of the Ocimum accessions, to select genotypes with higher yield of essential oil rich in linalool. Experiment design consisted of randomized blocks with two replications, evaluating 55 genotypes of the Germplasm Bank of Ocimum from the Universidade Federal do Sergipe, Brazil. The plant height, dry matter of the aerial plant parts, essential oil content and yield were evaluated. A wide diversity among the genotypes was observed for all morphological and agronomical traits evaluated. A large amplitude occurred among genotypes regarding the content of essential oil from 0,202 to 2,536 $\mathrm{ml} / 100 \mathrm{~g}$. For the essential oil yield an amplitude from 1,103 to 21,817 1/ha was observed. Evaluating the traits content and yield of $O$. basilicum essential oil the genotypes NSL6421, PI197442, PI358464, PI414194, PI531396 and 'Fino Verde' can be selected for breeding programs to obtain cultivars with a high yield of essential oil rich in linalool.
\end{abstract}

Keywords: Ocimum sp., germplasm, diversity, essential oil.

(Recebido para publicação em 21 de março de 2003 e aceito em 17 de novembro de 2003)

$\mathrm{O}$ manjericão (Ocimum basilicum L., Lamiaceae) é planta anual ou perene, dependendo do local em que é cultivado. Nos Estados Unidos da América o cultivo é de média escala e para fins culinários, ornamentais e extração de óleo essencial. Essa espécie é comercialmente cultivada para utilização de suas folhas verdes e aromáticas, usadas frescas ou secas como aromatizante ou tempero. De acordo com Lawrence (1993), a produção mundial de óleo essencial de manjericão em 1992 foi de 43 toneladas, equivalendo a 2,8 milhões de dólares. Só os EUA importaram em 1988, 1.806 toneladas de manjericão (folhas secas e óleo essencial), equivalente a 2,5 milhões de dólares (Simon, 1990). Esse valor aumentou para 4.195 toneladas de matéria seca em 1996, equivalente a 5,5 milhões de dólares (USDA, 1998).

A nomenclatura botânica correta para as espécies e variedades do gênero Ocimum da família Lamiaceae, da qual o manjericão comercial está incluído, é de grande interesse, uma vez que mais de 60 espécies e formas têm sido relatadas, sendo questionável a verdadeira identidade botânica do manjericão citado em algumas literaturas. Adificuldade em classificar mais de 60 variedades de Ocimum basilicum L. provavelmente se deve à ocorrencia de polinização cruzada facilitando hibridações, resultando em grande número de subespécies, variedades e formas.

De acordo com o aroma os manjericões podem ser classificados em doce, limão, cinamato ou canela, cânfora, anis e cravo. Porém, para as características morfológicas da planta o manjericão pode receber uma nomenclatura dependendo do porte, formato da copa, tamanho e coloração da folhagem (Simon, 1995; Perry, 1997). O conteúdo dos óleos essenciais pode caracterizar os manjericões em tipo Europeu, Francês ou Doce; Egípcio, Reunião ou Comoro; Bulgário, Java ou Cinamato de Metila, e Eugenol sendo o primeiro tipo o que contém principalmente linalol e metil-cavicol. O óleo essencial pode ser extraído das folhas e ápices com inflorescências através de hidrodestilações (Simon, 1985; Charles e Simon, 1990), sendo o óleo mais valorizado no mercado o de manjericão tipo Europeu (Simon et al., 1990), cujos principais constituintes são linalol (40,5 a 48,2\%) e metil-cavicol (estragol) (28,9 a 31,6\%) (Fleisher, 1981; Charles e Simon, 1990). O preço do óleo 
essencial de manjericão doce no mercado internacional atinge valor próximo a US\$ 110,00/litro. Esse valor sugere que a implantação da cultura do manjericão doce para obtenção de óleo essencial pode ser promissora e uma atividade alternativa para os produtores da região Nordeste.

Os vários tipos de manjericão relatados apresentam diferentes composições químicas.

Para se obter sabor e teor adequados dos princípios que compões os óleos essenciais, plantios de vários tipos de manjericão são realizados na mesma área. Isso resulta em colheita de mistura de sementes(Simon, 1985). Através de um programa de melhoramento genético poderiam ser obtidas cultivares uniformes e padronizadas na composição do óleo essencial. Assim poderiam ser obtidas cultivares adaptadas a determinada região, com alto rendimento de óleo essencial rico em linalol. Uma das fases mais importantes em programas de melhoramento genético é a seleção de genótipos com características desejadas. Assim, o conhecimento do germoplasma disponível é essencial.

O presente trabalho objetivou caracterizar morfológica e agronômicamente acessos de Ocimum sp. para seleção de indivíduos, uso no programa de melhoramento da UFS e seleção de cultivares adaptadas à região Nordeste do Brasil.

\section{MATERIAL E MÉTODOS}

O experimento foi conduzido no Campus Rural da Universidade Federal de Sergipe. Utilizou-se o delineamento experimental de blocos casualizados, com duas repetições, avaliando 55 genótipos do Banco de Germoplasma de Ocimum da UFS, sendo 39 acessos fornecidos pela North Central Regional PI Station, Iowa State University, EUA, 13 cultivares comerciais doadas pelas empresas Topseed e Johnny's Selected Seeds e três acessos coletados em São Cristóvão-SE (Tabela 1). Cada repetição foi constituída por uma fileira de 2,5 m com espaçamento de 0,5 $\mathrm{m}$ entre plantas e $0,8 \mathrm{~m}$ entre linhas.

Os genótipos em avaliação foram costituídos em sua maior parte pela espécie $O$. basilicum, com excessão dos genótipos PI 211715; PI 500952 e Alfavaca cravo (O. gratissimum) e do genótipo Holy (O. sanctum).
As mudas foram produzidas em ambiente protegido com tela sombrite $50 \%$, em bandejas de isopor com 128 alvéolos com volume $30 \mathrm{ml}$ de substrato por alvéolo, e realizou-se duas irrigações diárias. A mistura de substrato utilizada foi composta de pó-de-coco, esterco bovino, e casca de arroz carbonizada nas proporções 1:1:1, sendo escolhida em ensaios preliminares de composições de substrato. Após sete dias da semeadura ocorreu a emergência de $90 \%$ dos acessos, sendo que trinta dias após à semeadura as mudas foram transplantadas para o campo. Para a preparação do solo realizou-se limpeza e posterior calagem com calcário dolomítico para atingir saturação de bases de $60 \%$, dois meses antes da implantação do experimento. Como fonte de nutrientes empregou-se esterco de galinha na proporção de $27,5 \mathrm{~m}^{3} / \mathrm{ha}$. Após o primeiro corte efetuou-se nova suplementação na mesma proporção. Os tratos culturais incluiram capinas e irrigação por gotejamento.

As avaliações morfológicas foram realizadas aproximadamente dois meses após o plantio e em plena floração de pelo menos 50\% das plantas de cada acesso. Foram avaliadas (a) largura da copa (maior largura da copa, utilizando-se a média para representar a parcela); (b) diâmetro do caule (com o auxílio de paquímetro, na base do caule das plantas anotando-se a média para representar a parcela); (c) comprimento e largura das lâminas foliares (obtidas aleatoriamente duas folhas totalmente expandidas de cada planta das parcelas úteis; anotou-se as médias para representarem a parcela); (d) relação comprimento/largura das lâminas foliares (calculada dividindo-se o comprimento médio pela largura média das folhas amostradas de cada parcela útil); (e) hábito de crescimento (atribuiuse notas de 1 a 5 para as plantas da parcela útil, onde 1=planta ereta, nenhum galho toca o solo; $2=$ planta com $25 \%$ dos galhos baixeiros tocando o solo; $3=$ planta com $50 \%$ dos galhos baixeiros tocando o solo; 4=planta com $75 \%$ dos galhos baixeiros tocando o solo; $5=$ planta com $100 \%$ dos galhos baixeiros tocando o solo); (f) formato da copa (classificação em arredondado, forma de taça, irregular, outros); (g) cor das folhas e nervuras (de acordo com observações em campo); (h) cor das sépalas e pétalas (determinadas por ocasião da abertura das flores); (i) altura das plantas (obtida com o auxílio de fita métrica, utilizando-se a média para representar a parcela); (j) peso da matéria seca da parte aérea (corte das plantas a $20 \mathrm{~cm}$ do solo, entre 14:00 e 16:00 horas. Secagem em estufa com fluxo de ar forçado a $40^{\circ} \mathrm{C}$ até peso constante); (k) teor de óleo essencial [hidrodestilação com $50 \mathrm{~g}$ de biomassa seca com destilador tipo Clevenger (Guenther, 1972); teor expresso em ml/ $100 \mathrm{~g}$ de biomassa seca); (1) rendimento de óleo essencial expresso em $1 /$ ha.

\section{RESULTADOS E DISCUSSÃO}

A grande maioria dos genótipos avaliados apresentou plantas eretas, com exceção dos genótipos Ames 1700; PI 170581; PI 358468; PI 368697; OCI-030; OCI-032 e OCI-033 com 25\% dos galhos baixeiros tocando o solo. Em relação à coloração das folhas, foram verdes, fazendo exceção o PI 174285; PI 182246; Red Rubin; Osmin Purple (folhas roxas) e OCI-030 com folhas verde+amarela. Para coloração de nervura encontrou-se a maior parte verde, com exceção de PI 174285; PI 182246; Holy; Red Rubin; Osmin purple (nervura roxa) e PI 174284 com nervura verde+roxa.

Observou-se grande diversidade para as variáveis largura de copa, diâmetro do caule, comprimento de folha, largura de folha e relação comprimento/largura de folha de Ocimum sp. (Tabela 1). Quanto ao diâmetro do caule notou-se que $52,94 \%$ dos acessos de $O$. basilicum apresentaram diâmetro do caule superior ou igual a $1,0 \mathrm{~cm}$. Para a espécie $O$. gratissimum, os acessos PI 211715 e Alfavaca Cravo foram superiores com médias de 1,72 e 1,30 cm, enquanto a espécie $O$. sanctum apresentou diâmetro de $1,19 \mathrm{~cm}$ (Tabela 1). Para comprimento (C) e largura (L) e relação $\mathrm{C} / \mathrm{L}$ de folha verificou-se grande variabilidade (Tabela 1).

Não se obteve relação direta entre altura de planta e peso de matéria seca da parte aérea (Tabela 1). Suchorska e Osinsk (2001), avaliando cinco acessos de manjericão, observaram variação genotípica na determinação das características da planta; assim o acesso da Alemanha apresentou plantas mais baixas e o menor número de inflorescências, enquanto o egípcio apresentou as plantas mais altas e obteve um maior número de 
Tabela 1. Características de genótipos de Ocimum sp. Do Banco de Germoplasma da UFS. São Cristóvão (SE), UFS, 2002.

\begin{tabular}{|c|c|c|c|c|c|c|c|c|c|c|c|c|}
\hline \multirow[b]{2}{*}{ Genótipo } & \multirow[b]{2}{*}{ Form. copa } & \multicolumn{2}{|c|}{ Coloração } & \multirow{2}{*}{$\begin{array}{c}\text { Largura } \\
\text { copa }\end{array}$} & \multirow{2}{*}{$\begin{array}{c}\varnothing \\
\text { caule } \\
(\mathrm{cm})\end{array}$} & \multicolumn{3}{|c|}{ Folha } & \multirow[b]{2}{*}{ Alt. (cm) } & \multirow{2}{*}{$\begin{array}{c}\text { Peso/pl. } \\
\text { (g) }\end{array}$} & \multirow{2}{*}{$\begin{array}{c}\text { Teor } \\
\text { óleo } \\
(\mathrm{ml} / 100) \\
\end{array}$} & \multirow{2}{*}{$\begin{array}{c}\text { Rend. } \\
\text { óleo } \\
\text { essencial }\end{array}$} \\
\hline & & pétala & sépala & & & $\begin{array}{l}\text { comp- } \\
\text { r. (cm) }\end{array}$ & $\begin{array}{c}\text { Iargura } \\
(\mathrm{cm})\end{array}$ & $\begin{array}{l}\text { Rel. } \\
\text { C/L }\end{array}$ & & & & \\
\hline Ames 1700 & Arredondado & Branca & Verde & $18,75 \mathrm{e}$ & $0,44 d$ & $1,12 i$ & $2,00 f$ & $1,83 c$ & $20,250 \mathrm{e}$ & $11,739 f$ & $0,820 \mathrm{~d}$ & $2,503 d$ \\
\hline Ames 7772 & Arredondado & Branca & Verde & $41,25 d$ & $1,04 \mathrm{c}$ & $2,20 \mathrm{~h}$ & $3,40 \mathrm{e}$ & $1,55 \mathrm{~d}$ & $43,750 c$ & $26,412 \mathrm{e}$ & $0,467 e$ & $3,067 d$ \\
\hline NSL 6421 & Irregular & Branca & Verde & $52,75 \mathrm{c}$ & $1,25 b$ & $3,10 \mathrm{e}$ & $6,00 d$ & $1,94 \mathrm{c}$ & $62,500 \mathrm{~b}$ & $49,568 d$ & $0,692 d$ & $8,570 \mathrm{c}$ \\
\hline PI 170579 & Arredondado & Branca & Verde & $36,00 \mathrm{~d}$ & $1,22 b$ & $1,15 i$ & $2,25 f$ & $2,02 \mathrm{c}$ & $32,250 \mathrm{e}$ & $18,528 f$ & $0,759 d$ & $3,514 d$ \\
\hline 170581 & Arred & Branca & Verde & $38,75 d$ & $1,15 b$ & $1,00 \mathrm{i}$ & $1,85 f$ & $1,85 \mathrm{c}$ & $44,750 c$ & $46,897 d$ & $0,294 \mathrm{e}$ & $3,440 \mathrm{~d}$ \\
\hline PI 172996 & Taça & Branca & Verde+roxa & $34,25 d$ & $0,70 \mathrm{~d}$ & $2,35 \mathrm{~g}$ & $4,50 \mathrm{~d}$ & $1,92 \mathrm{c}$ & $45,500 c$ & $12,735 f$ & $0,378 \mathrm{e}$ & $1,202 d$ \\
\hline PI 172997 & Taça & Branca & Roxa & $40,00 d$ & $0,72 d$ & $1,75 \mathrm{~g}$ & $4,22 \mathrm{e}$ & $2,42 a$ & $58,250 \mathrm{~b}$ & $13,006 f$ & $0,340 \mathrm{e}$ & $1,103 d$ \\
\hline ㄱ 173746 & Arredondado & Branca & Verde & $38,75 d$ & $1,07 \mathrm{c}$ & $3,20 \mathrm{~d}$ & $6,75 d$ & $2,11 b$ & $48,750 \mathrm{c}$ & $21,570 f$ & $0,419 \mathrm{e}$ & $2,259 d$ \\
\hline PI 174284 & ndado & Branca & Roxa & $27,75 \mathrm{e}$ & $0,57 d$ & $2,20 f$ & $5,50 e$ & $2,48 a$ & $43,500 c$ & $24,022 e$ & $0,448 \mathrm{e}$ & $2,689 d$ \\
\hline PI 174285 & Arredondado & Roxa & Roxa & $30,87 \mathrm{e}$ & $0,67 d$ & $4,00 f$ & $5,50 \mathrm{c}$ & $1,38 d$ & $47,950 \mathrm{c}$ & $13,623 f$ & $0,592 d$ & $2,017 d$ \\
\hline PI 176646 & Taça & Branca & Verde & $25,50 \mathrm{e}$ & $0,55 d$ & $2,00 \mathrm{~h}$ & $3,00 \mathrm{e}$ & $1,50 \mathrm{~d}$ & $30,400 \mathrm{e}$ & $8,453 f$ & $0,628 \mathrm{~d}$ & $1,320 d$ \\
\hline PI 182246 & Arredc & Lilás & Roxa & $35,25 d$ & $1,00 \mathrm{c}$ & $2,25 \mathrm{e}$ & $5,75 \mathrm{e}$ & $2,57 a$ & $35,750 d$ & $14,034 f$ & $0,523 e$ & $1,835 d$ \\
\hline PI 190100 & Taça & Branca & Verde & $43,00 d$ & $1,07 \mathrm{c}$ & $3,45 d$ & $7,50 \mathrm{~d}$ & $2,17 b$ & $46,250 c$ & $16,645 f$ & $0,431 \mathrm{e}$ & $1,804 d$ \\
\hline PI 197442 & Arredc & Rósea & Roxa & $45,70 d$ & $1,32 b$ & $3,50 c$ & $9,25 d$ & $2,64 a$ & $45,500 c$ & $33,860 \mathrm{e}$ & $2,537 a$ & $21,817 b$ \\
\hline PI 207498 & Taça & Branca & Verde & $50,50 \mathrm{c}$ & $1,50 \mathrm{a}$ & $3,25 d$ & $7,00 \mathrm{~d}$ & $2,16 b$ & $62,400 b$ & $27,040 \mathrm{e}$ & $0,327 e$ & $2,183 d$ \\
\hline PI 211586 & Arred & Branca & Verde +1 & $27,75 \mathrm{e}$ & $0,72 d$ & $1,80 \mathrm{~g}$ & $4,75 \mathrm{e}$ & $2,63 a$ & $29,500 \mathrm{e}$ & $15,164 f$ & $0,618 d$ & $2,293 d$ \\
\hline PI 253157 & Taça & Branca & Verde & $32,50 \mathrm{e}$ & $1,01 \mathrm{c}$ & $3,90 \mathrm{~d}$ & $7,40 \mathrm{c}$ & $1,88 \mathrm{c}$ & $46,250 c$ & $31,165 \mathrm{e}$ & $0,330 \mathrm{e}$ & $2,536 \mathrm{~d}$ \\
\hline PI 296390 & Arredondado & Branca & Verde & $41,40 \mathrm{~d}$ & $1,02 \mathrm{c}$ & $2,75 \mathrm{e}$ & $5,75 d$ & $2,10 b$ & $52,650 c$ & $16,642 f$ & $0,769 d$ & $3,206 d$ \\
\hline PI 296391 & Arredondado & Branca & Verde & $50,75 \mathrm{c}$ & $1,17 \mathrm{~b}$ & $4,25 d$ & $8,00 c$ & $1,89 c$ & $75,000 a$ & $41,986 d$ & $0,202 e$ & $2,116 d$ \\
\hline PI 358464 & Arredondado & Branca & Verde+roxa & $28,75 \mathrm{e}$ & $0,71 d$ & $2,50 f$ & $5,25 d$ & $2,16 b$ & $31,000 \mathrm{e}$ & $14,950 f$ & $1,683 b$ & $6,054 \mathrm{c}$ \\
\hline PI 358467 & Arre & Branca & Verde & $50 d$ & $1,01 \mathrm{c}$ & $2,55 \mathrm{~g}$ & $4,55 d$ & $1,78 \mathrm{c}$ & $28,000 \mathrm{e}$ & $25,625 \mathrm{e}$ & $1,571 \mathrm{~b}$ & $10,067 \mathrm{c}$ \\
\hline PI 358468 & Arredondado & Branca & Verde & $30,00 \mathrm{e}$ & $0,77 d$ & $1,75 \mathrm{~h}$ & $2,75 \mathrm{e}$ & $1,58 d$ & $29,400 \mathrm{e}$ & $23,800 \mathrm{e}$ & $0,992 \mathrm{c}$ & $5,943 \mathrm{c}$ \\
\hline PI 358471 & Irregular & Branca & Verde & $27,75 \mathrm{e}$ & $0,90 \mathrm{c}$ & $1,60 \mathrm{~h}$ & $3,25 \mathrm{e}$ & $2,03 c$ & $27,000 \mathrm{e}$ & $13,995 f$ & $0,426 \mathrm{e}$ & $1,459 d$ \\
\hline PI 358472 & Arredondado & Branca & Verde & $29,02 e$ & $0,75 d$ & $2,80 d$ & $7,00 \mathrm{~d}$ & $2,50 a$ & $28,500 \mathrm{e}$ & $11,555 f$ & $1,957 b$ & $5,552 \mathrm{c}$ \\
\hline PI 368697 & Arredondado & Branca & Verde & & & & & $2,13 b$ & & & $0,281 \mathrm{e}$ & $2,732 d$ \\
\hline PI 368698 & Arredondado & Branca & Verde & $34,50 \mathrm{~d}$ & $1,05 c$ & $2,55 f$ & $5,00 d$ & $1,96 \mathrm{c}$ & $36,750 d$ & $45,240 d$ & $0,269 \mathrm{e}$ & $2,922 d$ \\
\hline PI 368699 & Arredo & Branca & Verde & $37,70 d$ & $1,07 \mathrm{c}$ & $2,00 \mathrm{~h}$ & $3,00 \mathrm{e}$ & $1,50 d$ & $34,200 d$ & $13,070 f$ & $0,540 \mathrm{e}$ & $1,699 d$ \\
\hline PI 368700 & Taça & Branca & Verde & $26,50 \mathrm{e}$ & $0,67 d$ & $1,75 \mathrm{~h}$ & $3,25 \mathrm{e}$ & $1,87 \mathrm{c}$ & $27,000 \mathrm{e}$ & $10,501 f$ & $1,031 \mathrm{c}$ & $2,722 d$ \\
\hline PI 379414 & Arredondado & Branca & Verde & $26,50 \mathrm{e}$ & $1,02 \mathrm{c}$ & $2,60 \mathrm{e}$ & $5,75 d$ & $2,21 b$ & $34,250 d$ & $17,609 f$ & $1,064 \mathrm{c}$ & $4,576 d$ \\
\hline PI 414193 & Arredondado & Branca & Verde & $41,40 d$ & $1,33 a$ & $2,00 \mathrm{~h}$ & $3,00 \mathrm{e}$ & $1,50 \mathrm{~d}$ & $32,000 \mathrm{e}$ & $16,140 f$ & $0,591 \mathrm{~d}$ & $2,385 d$ \\
\hline PI 414194 & Arredondado & Rósea & Verde+roxa & $59,50 \mathrm{~b}$ & $1,25 b$ & $3,00 \mathrm{e}$ & $6,50 d$ & $2,17 b$ & $54,540 \mathrm{c}$ & $67,000 \mathrm{~b}$ & $0,525 \mathrm{e}$ & $8,963 \mathrm{c}$ \\
\hline PI 414197 & Taça & Branca & Verde & $18,00 \mathrm{e}$ & $0,67 d$ & $2,40 f$ & $5,25 d$ & $2,18 b$ & $36,500 d$ & $15,370 f$ & $0,394 \mathrm{e}$ & $1,513 d$ \\
\hline PI 414198 & Taça & Branca & Verde+roxa & $38,25 d$ & $0,92 c$ & $2,05 \mathrm{~g}$ & $4,00 \mathrm{e}$ & $1,95 \mathrm{c}$ & $40,900 d$ & $14,770 f$ & $0,468 \mathrm{e}$ & $1,739 d$ \\
\hline PI 414199 & Arredondado & Rósea & Roxa & $31,75 \mathrm{e}$ & $1,00 c$ & $2,30 \mathrm{~g}$ & $4,40 \mathrm{e}$ & $1,91 \mathrm{c}$ & $35,250 d$ & $14,178 f$ & $0,398 \mathrm{e}$ & $1,415 d$ \\
\hline PI 414200 & Arredondado & Rósea & Roxa & $59,50 \mathrm{~b}$ & $1,50 a$ & $2,90 \mathrm{~d}$ & $7,75 d$ & $2,67 a$ & $52,000 c$ & $20,338 f$ & $1,117 \mathrm{c}$ & $5,688 \mathrm{c}$ \\
\hline PI 500944 & Taça & Lilás & Verde & $38,50 d$ & $0,97 \mathrm{c}$ & $3,55 \mathrm{c}$ & $8,25 d$ & $2,33 b$ & $47,000 c$ & 26,877 e & $1,133 c$ & $6,549 \mathrm{c}$ \\
\hline PI 531396 & Arredondado & Branca & Verde & $21,50 \mathrm{e}$ & $0,50 \mathrm{~d}$ & $2,50 \mathrm{e}$ & $5,80 d$ & $2,31 b$ & $26,500 \mathrm{e}$ & $18,800 f$ & $0,915 d$ & $4,293 d$ \\
\hline PI 211715 & Arredondado & Branca & Verde & $80,50 a$ & $1,72 \mathrm{a}$ & $3,50 \mathrm{c}$ & $9,00 d$ & $2,57 a$ & $81,100 a$ & $77,490 \mathrm{~b}$ & $1,350 \mathrm{c}$ & $26,295 a$ \\
\hline PI 500952 & Arredondado & Branca & Verde & $37,40 \mathrm{~d}$ & $0,84 \mathrm{c}$ & $3,00 \mathrm{~d}$ & $7,00 \mathrm{~d}$ & $2,33 b$ & $48,475 c$ & $22,265 \mathrm{e}$ & $0,193 e$ & $1,064 d$ \\
\hline Genovese & Taça & Lilás & Verde & $34,00 d$ & $0,80 \mathrm{~d}$ & $3,50 \mathrm{~d}$ & $7,50 \mathrm{~d}$ & $2,14 b$ & $60,000 \mathrm{~b}$ & $16,268 f$ & $0,445 \mathrm{e}$ & $1,810 \mathrm{~d}$ \\
\hline Mrs. Burns & Arredondado & Lilás & Verde & $37,00 \mathrm{~d}$ & $0,92 \mathrm{c}$ & $2,90 \mathrm{e}$ & $6,30 \mathrm{~d}$ & $2,17 b$ & $40,000 d$ & $29,340 \mathrm{e}$ & $1,050 \mathrm{c}$ & $7,539 \mathrm{c}$ \\
\hline Sweet Dani & Arredondado & Branca & Verde & $29,50 \mathrm{e}$ & $0,85 c$ & $2,25 f$ & $5,25 \mathrm{e}$ & $2,35 b$ & $45,500 c$ & $15,142 f$ & $0,612 d$ & $2,270 d$ \\
\hline Cinnamom & Arredondado & Lilás & Roxa & $39,75 d$ & $1,17 b$ & $2,65 \mathrm{~g}$ & $4,75 d$ & $1,79 c$ & $33,500 d$ & $33,920 f$ & $1,275 \mathrm{c}$ & $10,413 c$ \\
\hline Licorice & Arredondado & Lilás & Roxa & $38,00 d$ & $0,92 c$ & $2,95 \mathrm{e}$ & $6,00 d$ & $2,04 \mathrm{c}$ & $39,500 d$ & $14,133 \mathrm{e}$ & $0,393 e$ & $1,415 d$ \\
\hline Alfavaca cravo & Arredondado & Branca & Verde & $61,50 \mathrm{~b}$ & $1,30 b$ & $6,30 \mathrm{~b}$ & $9,75 b$ & $1,87 \mathrm{c}$ & $57,500 \mathrm{~b}$ & $57,620 c$ & $0,550 \mathrm{e}$ & $8,082 \mathrm{c}$ \\
\hline OCl-030 & Arredondado & Branca & Verde & $35,40 \mathrm{~d}$ & $0,85 \mathrm{c}$ & $2,25 \mathrm{~g}$ & $4,60 \mathrm{e}$ & $2,06 c$ & $26,750 \mathrm{e}$ & $13,315 f$ & $0,620 \mathrm{~d}$ & $2,041 d$ \\
\hline OCI-032 & Arredondado & Lilás & Verde & $50,40 c$ & $1,08 \mathrm{c}$ & $1,00 \mathrm{~h}$ & $2,50 f$ & $2,50 a$ & $41,500 d$ & $27,320 \mathrm{e}$ & $1,051 \mathrm{c}$ & $6,829 c$ \\
\hline
\end{tabular}

*Valores com letras iguais, nas colunas, não diferem entre si pelo teste de Scott-Knott (p£0,05)

${ }^{1 / R e l}$. C/L = Relação entre comprimento da folha/largura da folha 
A. F. Blank et al.

Tabela 1. Características de genótipos de Ocimum sp. Do Banco de Germoplasma da UFS. São Cristóvão (SE), UFS, 2002. (Continuação)

\begin{tabular}{|c|c|c|c|c|c|c|c|c|c|c|c|c|}
\hline \multirow[b]{2}{*}{ Genótipo } & \multirow[b]{2}{*}{ Form. copa } & \multicolumn{2}{|c|}{ Coloração } & \multirow{2}{*}{$\begin{array}{c}\text { Largura } \\
\text { copa }\end{array}$} & \multirow{2}{*}{$\begin{array}{c}\varnothing \\
\text { caule } \\
(\mathrm{cm})\end{array}$} & \multicolumn{3}{|c|}{ Folha } & \multirow[b]{2}{*}{ Alt. (cm) } & \multirow{2}{*}{$\begin{array}{c}\text { Peso/pl. } \\
\text { (g) }\end{array}$} & \multirow{2}{*}{$\begin{array}{c}\text { Teor } \\
\text { óleo } \\
(\mathrm{ml} / 100)\end{array}$} & \multirow{2}{*}{$\begin{array}{c}\text { Rend. } \\
\text { óleo } \\
\text { essencial }\end{array}$} \\
\hline & & pétala & sépala & & & $\begin{array}{l}\text { comp- } \\
\text { r. (cm) }\end{array}$ & $\begin{array}{c}\text { Iargura } \\
\text { (cm) }\end{array}$ & $\begin{array}{l}\text { Rel. } \\
\text { C/L' }\end{array}$ & & & & \\
\hline $\mathrm{OCl}-033$ & Arredondado & Branca & Verde & $73,54 a$ & $1,45 a$ & $0,50 \mathrm{j}$ & $1,00 f$ & $2,00 c$ & $48,125 c$ & $92,950 a$ & $1,300 \mathrm{c}$ & $30,082 a$ \\
\hline Fino Verde & Arredondado & Branca & verde & $59,02 b$ & $1,61 \mathrm{a}$ & $2,50 \mathrm{~h}$ & $3,50 \mathrm{~d}$ & $1,40 \mathrm{~d}$ & $53,475 c$ & $52,100 d$ & $0,667 d$ & $8,678 \mathrm{c}$ \\
\hline Holy & Taça & Roxa & Roxa & $51,90 c$ & $1,19 b$ & $3,00 \mathrm{~d}$ & $8,00 \mathrm{~d}$ & $2,67 a$ & $57,400 \mathrm{~b}$ & $28,350 \mathrm{e}$ & $0,900 \mathrm{~d}$ & $6,336 c$ \\
\hline Red Rubin & Arredondado & Rósea & Roxa & $42,87 d$ & $0,84 \mathrm{c}$ & $5,00 \mathrm{~b}$ & $10,00 \mathrm{c}$ & $2,00 \mathrm{c}$ & $42,625 d$ & $20,500 f$ & $0,744 d$ & $3,803 d$ \\
\hline Mammouth & Arredondado & Branca & Verde & $45,40 d$ & $1,27 b$ & $7,50 a$ & $11,00 a$ & $1,47 d$ & $40,800 d$ & $38,000 \mathrm{e}$ & $0,836 d$ & $7,779 \mathrm{c}$ \\
\hline Spicy Bush & Arredondado & Branca & Verde & $40,40 d$ & $1,08 \mathrm{c}$ & $1,00 \mathrm{~h}$ & $2,50 f$ & $2,50 a$ & $28,100 \mathrm{e}$ & $24,800 \mathrm{e}$ & $1,541 b$ & $9,769 \mathrm{c}$ \\
\hline Osmin Purple & Taça & Rósea & Roxa & $29,00 \mathrm{e}$ & $0,68 d$ & $3,00 \mathrm{~d}$ & $7,00 \mathrm{~d}$ & $2,33 b$ & $35,665 d$ & $12,333 f$ & $0,963 \mathrm{c}$ & $2,997 d$ \\
\hline $\begin{array}{l}\text { Italian Large } \\
\text { Leaf }\end{array}$ & Arredondado & Branca & Verde & b & $1,54 a$ & $00 \mathrm{e}$ & $6,00 \mathrm{~d}$ & $2,00 c$ & $59,325 b$ & $63,050 c$ & $00 \mathrm{~d}$ & $11,307 \mathrm{c}$ \\
\hline
\end{tabular}

*Valores com letras iguais, nas colunas, não diferem entre si pelo teste de Scott-Knott $(\mathrm{p} £ 0,05)$

${ }^{1 / R e l}$. C/L = Relação entre comprimento da folha/largura da folha

inflorescências. Observou-se que a planta com maior altura não resultou no maior peso de matéria seca da parte aérea. Isso, provavelmente, é devido à interação do diâmetro da copa, do espaçamento entre-nós, do tamanho de folhas e do número de folhas por plantas.

Os acessos que se destacaram quanto ao peso de matéria seca da parte aérea por planta foram OCI-33, PI211715 e PI414194 com pesos de 92,95, 77,49 e $67,00 \mathrm{~g} /$ planta, respectivamente. Dentro das cultivares comerciais de $O$. basilicum o Italian Large Leaf e o Fino Verde destacaram-se significativamente com pesos de 63,05 e 52,10 g/planta.

Quanto à espécie $O$. basilicum, os genótipos PI197442 e PI358472 apresentaram os maiores teores de óleo essencial com 2,536 e 1,957 ml/100 g, enquanto que o OCI-33 e PI197442 apresentaram os maiores rendimentos com 30,081 e 21,817 1/ha (Tabela 3 ). O acesso de $O$. gratissimum mais produtivo foi $\mathrm{PI} 211715$ com teor de óleo essencial de $1,350 \mathrm{ml} /$ $100 \mathrm{~g}$ e produtividade de 26,295 1/ha. Observou-se que $30 \%$ dos acessos apresentaram rendimento de óleo essencial acima de 6 1/ha (Tabela 1). Em trabalho realizado por Suchorska e Osinsk (2001) foi observada variação de 0,1 a $0,55 \%$ de óleo essencial.

Os genótipos de $O$. basilicum que se mostraram mais promissores quanto ao teor, rendimento e linalol (dados não apresentados) no óleo essencial foram NSL6421 (81,40\% de linalol), PI358464 (79,38\% de linalol), PI531396 (78,30\% de linalol), PI414194 (71,62\% de linalol),
PI197442 (61,57\% de linalol) e 'Fino Verde' (77,04\% de linalol). Estes poderão ser usados em programa de melhoramento genético visando a obtenção de novas cultivares com alto rendimento de óleo essencial rico em linalol. Esta grande variação no rendimento de óleo essencial para as diferentes cultivares, também foi relatada por Charles e Simon (1990), Simon (1995) e Morales e Simon (1997). O acesso PI 211715 (72,42\% de linalol) também apresentou resultados promissores quanto às variáveis acima citadas e poderá ser usado para desenvolver uma cultivar de O. gratissimum rica em linalol. Suchorska \& Osinsk (2001), estudando cinco acessos de manjericão doce, observaram que o óleo essencial do acesso do Egito, tipo egípcio, foi diferente dos demais países (Alemanha, Romênia e Hungria), que apresentaram acessos com óleo essencial tipo Europeu.

Avaliando teor e rendimento de óleo essencial de $O$. basilicum pode-se selecionar os genótipos NSL6421, PI197442, PI358464, PI414194, PI531396, e 'Fino Verde' para o programa de melhoramento genético que visa a obtenção de novas cultivares de manjericão com alto rendimento de óleo essencial rico em linalol. Esses seis genótipos provavelmente apresentam um conjunto de genes que poderão ser utilizados para compor uma cultivar de O. basilicum promissora.

\section{AGRADECIMENTOS}

Os autores agradecem ao ETENE/ FUNDECI/BN pelo financiamento desta pesquisa e ao CNPq pela concessão da bolsa de produtividade ao coordenador do programa de melhoramento de manjericão Prof. Arie F. Blank.

\section{LITERATURA CITADA}

CHARLES, D.J.; SIMON, J.E. Comparison of extraction methods for the rapid determination of essential oil content and composition of basil (Ocimum spp.). Journal of the American Society for Horticultural Science, v.115, n.3, p.458-462, 1990. FLEISHER, A. Essential oils from two varieties of Ocimum basilicum L. grown in Israel. Journal of the Science of Food and Agriculture, v.32, p.1119-1122, 1981.

GUENTHER, E. The essential oils. Malabar: Krieger, 1972. 427 p.

LAWRENCE, B.M. A planning scheme to evaluate new aromatic plants for the flavor and fragrance industries. In: JANICK, J.; SIMON, J.E. (Eds.). New crops. New York: Wiley, 1993. p.620-627.

MORALES, M.R.; SIMON, J.E. 'Sweet Dani': a new culinary and ornamental lemon basil. HortScience, v.32, n.1, p.148-149, 1997.

PERRY, L. Ocimum (parte do curso PSS123 de 1997). Vermont: University of Vermont, 1997. 3 p. (Apostila)

SIMON, J.E. Basil. West Lafayette: Purdue University, 1995. 6 p. (Boletim).

SIMON, J.E. Essential oils and culinary herbs. In: JANICK, J.; SIMON, J.E. (Eds.). Advances in new crops. Portland: Timber Press, 1990. p.472-483.

SIMON, J.E.; QUINN, J.; MURRAY, R.G. Basil: a source of essential oils. In: JANICK, J.; SIMON, J.E. (Eds.). Advances in new crops. Portland: Timber Press, 1990. p. 484-489.

SIMON, J.E. Sweet basil: a production guide. West Lafayette: Purdue University, 1985. 3p. (Boletim). SUCHORSKA, T.K.; OSINSK, A.E. Morphological developmental and chemical analyses of 5 forms of sweet basil (Ocimum basilicum L.). Annals of Warsaw Agricultural University, n.22, p.17-22, 2001.

USDA. Tropical products: world markets and trade. FAS/USDA, 1998. Disponível em <http:// ffas.usda.gov/htp/tropical/1998/98\%2D03/ troptoc.htm>. Acesso em 28/09/98. 